\title{
Educação inclusiva, ensino de Ciências e linguagem científica: possíveis relaçōes
}

\author{
Anna Maria Canavarro Benite* \\ Claudio Roberto Machado Benite** \\ Eveline Borges Vilela-Ribeiro ${ }^{* * *}$
}

\section{Resumo}

Atualmente, reclama-se por uma Educação Inclusiva na Sociedade da Informação. Dessa forma, é urgente se ensinar ciências no mundo onde o saber científico e tecnológico é cada dia mais valorizado, admitindo que não é possível a formação de um cidadão crítico sem conhecimentos básicos necessários para a realização de julgamentos e conseqüentes opçôes. O exercício da cidadania exige a participação efetiva dos indivíduos, tenham eles necessidades educativas especiais (NEE) ou não, em todas as esferas da sociedade. Neste artigo, serão apresentados alguns apontamentos sobre a relação complexa entre educação inclusiva, ensino de ciências e linguagem científica, assumindo a urgência da compreensão de necessidades específicas que possam orientar o ensino de ciências para este grupo social. Completa este trabalho uma breve discussão sobre as características do conhecimento científico.

Palavras-chave: Ensino de Ciências; Educação Inclusiva; Linguagem científica.

\footnotetext{
* Professora Doutora da Universidade Federal de Goiás. Goiânia, Goiás, Brasil.

** Professor Doutor da Universidade Federal de Goiás. Goiânia, Goiás, Brasil.

*** Doutoranda da Universidade Federal de Goiás. Goiânia, Goiás, Brasil.
} 


\section{Inclusive education, Science teaching and scientific language: possible relationships}

\section{Abstract}

Nowadays, we want an inclusive education at the Society of Information. Thus, it is urgent to teach science in a world where scientific and technologic knowledge is increasingly valued, assuming that is not possible to form a critical citizen without basic knowledge that is needed to conduct trials and options. The exercise of citizenship requires active participation of individuals, with special educational needs or not, in all spheres of society. We intend this paper to present some notes about the complex relationship between inclusive education, science education and scientific language, assuming the urgency of understanding specific needs that can inform science education for this social group. This work is completed with a brief discussion of the characteristics of scientific knowledge.

Keywords: Science Education; Inclusive education; Scientific language.

\section{À guisa da introdução...}

A coexistência com igualdade de direitos de diferentes comunidades étnicas, grupos lingüísticos, confissôes religiosas e formas de vida, não pode ser obtida ao preço da fragmentação da sociedade. O processo doloroso do desacoplamento náo deve dilacerar a sociedade numa miríade de subculturas que se enclausuram mutuamente (HABERMAS, 2007, p. 172).

Hoje, a Educação Inclusiva (EI) é um dos temas mais discutidos no campo educacional em todo o mundo, haja visto sua incidência nas propostas políticas nacionais e internacionais. Para além do desafio de implementar as mais variadas estratégias de inclusão (programas, políticas, etc..), pesquisadores da área advogam a necessidade de transformação da escola, cabendo a ela adaptar-se às características de todo aluno, o que leva, necessariamente, a uma ruptura, por parte dos protagonistas, com o "status quo" e com as posturas mais resignadas dentro do modelo tradicional de ensino (MANTOAN, 2006).

A palavra de ordem na EI é o reconhecimento das diferenças individuais que se encontram no ambiente educacional, entendendo estas como uma construçáo pessoal e intransferível, pois "a diferença é, antes de mais nada, uma construção social histórica e culturalmente situada” (RODRIGUES, 2006, p. 305).

Em consonância a este movimento mundial de inclusão, o desenvolvimento de sistemas educacionais inclusivos é uma prioridade do governo brasileiro. $\mathrm{O} \mathrm{Mi}$ nistério da Educação tem como referência os princípios de educação para todos e a atenção à diversidade, assumindo compromisso com a incorporação deste marco conceitual nas políticas educacionais e na legislação, com o propósito de transformar o sistema educacional nacional em inclusivo (BRASIL, 2001, 2002, 2003). 
Como possível modalidade de organização didática e administrativa do sistema escolar, a EI tem se instituído como desafio para estudantes, pais, professores, administradores, legisladores, pesquisadores e sociedade em geral. Fato este que é deflagrado devido às controversas interpretaçôes de seu significado e de sua clientela.

Neste contexto, necessário é identificar quem são os excluídos do processo de escolarização, já que a escola, tradicionalmente, tem apresentado uma forte tendência seletiva. Nesse sentido, a história da educação brasileira é marcada pela exclusão e essa questáo se complexifica porque a desigualdade acaba se compondo por mecanismos de rejeição e estigmatização, atingindo indivíduos em situação com necessidades educativas especiais, negros, índios, migrantes e trabalhadores braçais (HADDAD, 2007).

Em relação à inclusão de alunos com necessidades educativas especiais, o Ministério da Educação, por meio da Secretaria de Educação Especial, tem implementado açóes para promover e garantir o acesso à educação nas escolas comuns do ensino regular em todos os estados brasileiros (BRASIL, 2002).

Entretanto, a concepção de atendimento escolar para os alunos com necessidades educativas especiais foi se definindo no transcorrer das fases pelas quais evoluíram os nossos serviços de Educação Especial: do seu período inicial, eminentemente assistencial que se definiu a partir de um modelo médico-psicológico e, posteriormente, a fase que se caracterizou pela inserção dos seus serviços em nosso sistema geral de ensino, englobando as propostas de inclusáo. Essas formas de atendimento nos fizeram chegar a um momento em que não se pode mais admitir a segregaçáo e a discriminaçáo escolar de alunos com necessidades educativas especiais.

\section{Sobre as dificuldades para lidar com as NEE}

A clareza registrada nas normativas legais, quando transferida para a execuçáo do ato pedagógico, transforma-se em açóes de alto grau de complexidade pelas dificuldades implícitas na sua realização. Passaremos agora a tecer considerações sobre algumas destas dificuldades.

Entre os fatores determinantes do sucesso ou insucesso da EI, se encontra a necessidade de formar professores aptos a executar a tarefa de lidar com educandos especiais. Ademais, segundo Vitaliano (2008), as principais dificuldades para lidar com alunos com NEE são:

- como abordar o aluno com NEE;

- como identificar os procedimentos de ensino adequados ao estudante com NEE;

- como identificar a necessidade educativa especial do estudante;

- como saber que o estudante com NEE é capaz de realizar as atividades propostas;

- como integrar o estudante na turma; 
- como proceder para não piorar as dificuldades do estudante com NEE;

- como evitar assumir uma atitude paternalista em relação ao estudante com NEE.

As razóes invocadas com maior frequência por pais, professores e gestores educacionais, para justificar o atraso na adoção de propostas educacionais inclusivas, dizem respeito a obstáculos humanos e materiais. Dentre os quais: escolas que carecem de possibilidades de acesso físico a alunos com deficiências motoras; salas de aula superlotadas; falta de recursos especializados para atender às necessidades de alunos com deficiências sensoriais; necessidade de se dominar a Língua Brasileira de Sinais (LIBRAS) e de intérpretes para os alunos surdos; ausência ou distanciamento de serviços de apoio educacional ao aluno e professor; resistência de professores, que alegam falta de preparo para atender os alunos com deficiência, nas salas de aulas comuns; reticências dos pais de alunos com e sem deficiência, entre outros.

\section{Sobre a especifidade do ensino de ciências na educação inclusiva}

A Educação Brasileira está fundamentada no princípio da igualdade: “do reconhecimento dos direitos humanos e o exercício dos direitos e deveres da cidadania" (BRASIL, 1998). Considerando que a cidadania se refere à participação efetiva dos indivíduos, tenham eles necessidades educativas especiais ou não, em todas as esferas da sociedade, torna-se evidente a necessidade do ensino de ciências. Deve-se ensinar Ciências para permitir ao cidadão ser protagonista do mundo que vive.

Dada a especificidade do ensino de ciências, alguns problemas lhes são característicos e recorrentes, tais como a dificuldade da transposição da linguagem científica, a falta de licenciados em ciências e o excesso de conteúdos. Por sua vez, resultados de nossas pesquisas demonstram que a principal dificuldade para ensinar ciências na sala de aula inclusiva é a falta de compreensão sobre a natureza do conhecimento científico (BENITE, et al., 2008 e 2009; PROCÓPIO et al., 2010). Desta maneira, passamos a discorrer sobre o conhecimento científico.

\section{A estrutura da Ciência}

O conhecimento científico é produzido num contexto social e por isso é necessariamente influenciado pelos objetivos pessoais e profissionais dos cientistas, pelos interesses e prioridades das agências de fomento à pesquisa e pela conjuntura de influências econômica, política e ética que impregna o contexto sociocultural do qual o cientista faz parte. Em outras palavras, o conhecimento científico é socialmente construído por meio das práticas da comunidade científica em resposta às demandas, necessidades e interesses de uma comunidade mais ampla que a financia e rodeia. Ademais, os procedimentos da ciência são baseados em convençóes que são elas próprias constructos humanos. Isto é:

[...] o conhecimento científico é o "que o cientista diz que é" e por esta razão passível de mudança. A ciência não é melhor do que qualquer outra forma de conhecimento acerca dos fenômenos naturais, mas somente, uma forma. (HODSON, 2009 p. 152). 
Apresentamos uma visão geral da relação entre a estrutura teórica (modelo científico) e a estrutura do mundo real na figura 1.

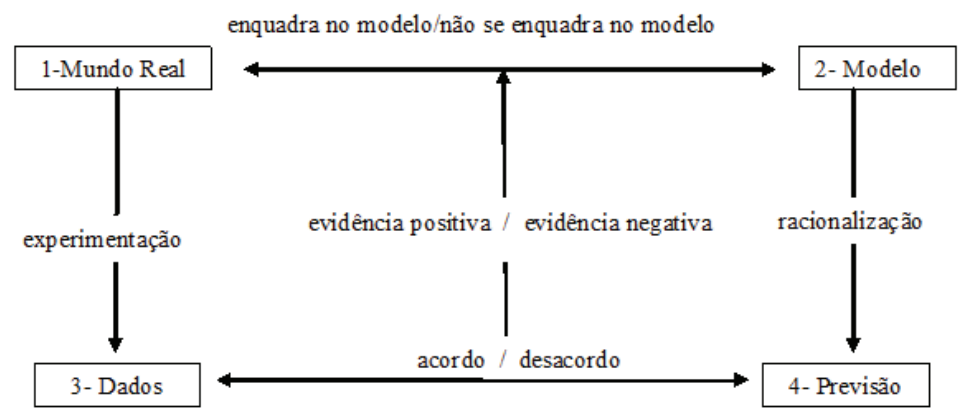

Figura 1 - Esquema para relacionar dados, racionalização e argumentação (Adaptado de Driver et al., 2000).

Os cientistas constroem modelos (teorias) capazes de representar alguns aspectos importantes do mundo real e com estes modelos podem fazer previsóes específicas inerentes ao curso do mundo real. Aceitar uma teoria científica não é somente materializar a resolução empírica e conceitual de um problema, mas conciliar a estrutura explicativa proposta com o nosso amplo quadro de hipóteses sobre o mundo.

Consideramos, apoiados em Hodson (2009), que, para aprender ciências, se deve considerar que a investigação científica se compóe de quatro fases:

- a fase de design e planejamento, que envolve: identificação de problemas, formular questóes, etc;

- a fase de realização, que envolve: operaçóes de coleta de dados e checagem destes;

- a fase de reflexão, que envolve: interpretação dos resultados em termos de bases teóricas, consideraçôes dos argumentos estabelecidos, etc.;

- e a fase de relato e revisão, que envolve: racionalizar os resultados, interpretaçáo, justificativas, produçáo de registros pessoais ou comunicaçóes à comunidade científica.

Desta forma, é a linguagem científica que distingue a ciência de outras formas de conhecimento e esta se efetiva como uma barreira potencial para o aprendizado de ciências e como fator de controle de acesso à ciência (BENITE, et al., 2008 e 2009; PROCÓPIO et al., 2010).

$\mathrm{O}$ uso da linguagem social e culturalmente contextualizada deve respeitar sua constituição linguística funcional, pois, só assim a linguagem funcionará como um recurso para significar a açáo. Portanto, é preciso considerar as particularidades da linguagem científica. 


\section{Sobre a linguagem científica e o ensino de ciências}

A temperatura cai quando o nitrato de ammonium se dissolve na água, porque as entalpias de hidratação dos íons ammonium e nitrato são menores que a energia de rede do nitrato de ammonium. (HODSON, 2009, p. 163)

Esta afirmação apresenta aspectos que podem ser entendidos como as principais características da linguagem científica:

a) É expressa em linguagem muito especializada e não em termos coloquiais. $\mathrm{A}$ linguagem científica inclui palavras construídas em contextos particulares, com raízes gregas e latinas, tais como ammonium.

Em geral, a utilização destas palavras pode representar dificuldades para os alunos se o professor não introduzi-las com a preocupação de significá-las. Hodson (2005) argumenta que, até mesmo palavras mais comuns, tais como: contrato, eficiente e abundância e ambos seus opostos, em geral, se não explicadas não são compreendidas pelos estudantes nas aulas de ciências.

b) Contém mais palavras essenciais por frase do que a linguagem cotidiana. Por exemplo, um problema para o estudante pode aparecer frente a uma argumentação, tal como: Uma vez que a transcrição foi iniciada com êxito, a RNA polimerase continua ao longo da molécula de DNA até encontrar sequências de terminação sobre a fita de DNA não transcrita.

A linguagem científica é muito mais densa que a linguagem coloquial, pois as palavras utilizadas têm significado dentro do corpo teórico que as sustenta. A ciência também faz uso de palavras do cotidiano, mas as utiliza dentro de contexto especializado, ou seja, o contexto científico. São exemplos o uso dos termos: força, energia e trabalho, na física; elemento, condutor ou composto, em química. O sentido conferido a estas palavras no contexto social pode representar um desafio para os estudantes em significá-las no contexto científico.

Um dos maiores problemas na aprendizagem de ciências, que é usualmente reforçado pelo excesso de definiçôes apresentados nos livros didáticos e por sistemas de avaliação que privilegiam a reprodução integral destas definiçôes, é a apresentação do conhecimento científico como imutável e verdadeiro. Como exemplo, poderíamos citar o conceito de função química como conjunto de substâncias com propriedades químicas semelhantes. Assim, sal é uma espécie de elevado caráter iônica, enquanto óxido é composto binário de oxigênio. Ora, o óxido de cálcio $(\mathrm{CaO})$ apresenta caráter iônico de $79 \%$ e é composto binário de oxigênio. Então, como classificar esta funçãa? Este composto é sal ou óxido? A pergunta pode ser respondida se considerarmos que as definiçõos aqui expostas para sal e óxido estão fundamentadas em critérios constitucionais, de modo que não é possível atribuir propriedades funcionais a estes compostos (CAMPOS; SILVA, 1999). 
Outro exemplo de conceitos ensinados como verdade: ácido tem sabor azedo. Só o ácido que tem em sua composição o grupamento carboxila tem sabor azedo. E os outros, como seriam classificados diante desta verdade?

Devido à noção de relatividade no comportamento das espécies químicas, só podemos definir as chamadas funçóes químicas, tais como ácidos ou bases, em termos de seus comportamentos químicos: comportamento ácido ou comportamento básico.

Dessa forma, as definiçóes de ácidos e bases de Arrhenius, Bronsted, Lewis e Unsanovich, apesar de abrangências e significados diferentes, estão articuladas pela definição comportamental dada às espécies. Por exemplo, segundo Arrhenius, ácidos são compostos que em solução aquosa ionizam-se produzindo como íon positivo $\mathrm{H}+$. Por isso, não se pode escolher um desses conceitos de ácido e base esperando descrever de modo racional todas as reaçóes químicas em qualquer solvente.

A utilização da linguagem científica envolve compreensão considerável da base conceitual que sustenta esta linguagem.

c) É uma integração sinérgica de palavras, gráficos, diagramas, figuras, equaçôes, tabelas e outras formas de expressão matemática (LEMKE, 1998).

Dessa forma, aprender ciências significa aprender como estas diferentes formas de representaçáo interagem entre si e suportam umas as outras.

d) A comunicação científica também é distinta, pois, é expositiva, analítica, impessoal e faz pouca ou nenhuma utilização de componentes metafóricos ou figurativos.

Por sua vez, a comunicação científica é expressa na voz passiva e no passado. A enculturação científica implica em ser capaz de usar a linguagem científica de forma adequada e ser capaz de apresentar idéias e resultados nos diferentes gêneros da ciência, incluindo relatórios científicos, tais como, relatórios de trabalho em laboratório.

Por tudo que foi aqui exposto, a linguagem científica permanecerá sempre uma barreira para a aprendizagem, portanto, um grande obstáculo ao acesso à ciência. Esse obstáculo ainda se apresenta maior, por exemplo, quando se relaciona às pessoas que não utilizam a linguagem oral, mas sim a gestual, já que ainda não existem terminologias adequadas para representar essas palavras em Libras (PEREIRA, et al, 2011; SOUSA, SILVEIRA, 2011).

\section{Algumas considerações finais...}

Para implementar qualquer proposta de EI, entre outros fatores, é primordial estabelecer uma prática educacional compromissada com a diversidade da sala de aula, ou seja, com as particularidades presentes em cada aluno ou em um grupo de alunos. Isso implica na promoção de uma formação de professores consistente, que englobe os conteúdos e as estratégias metodológicas necessárias para que o professor possa atuar com alunos com necessidades educativas especiais de modo responsável, na promoçáo do processo de ensino e de aprendizagem. 
A educação inclusiva nega todas as formas de exclusão e discriminação, independentemente de elas terem se originado como uma resposta da sociedade à diferença, ao gênero, a etnia a orientação sexual ou a pobreza. Finalmente, ensinar ciências, nesta perspectiva, é admitir que o conhecimento científico não é linear, rígido e infalível. É um produto do homem e por isso está sujeito a falhas, correçôes e adaptaçôes ao longo do tempo. E, deste modo, não se deve apresentar o conhecimento científico a qualquer aluno como pronto e acabado, pois esta é uma das formas de proporcionar uma falsa visão da ciência aos estudantes.

A linguagem científica tem papel central no ensino de ciências, pois, através de sua apresentação, são expressas explicaçôes para as entidades científicas. Defendemos que, quando professores de ciências reconhecem a natureza simbólica do conhecimento científico, estes têm mais subsídios para promover seu aprendizado em qualquer sala de aula. Defendemos que, para que um aprendiz se aproprie de um conceito científico, este deve ser apresentado não como um conhecimento isolado, mas como elemento estrutural da ciência.

No contexto da educação inclusiva, esses pressupostos devem ser mais evidentes ainda, com a finalidade de tornar o conhecimento científico acessível a todas às pessoas, englobando as diferentes necessidades de aprendizagem de cada sujeito.

\section{Referências}

BENITE, A. M. C.; et al. Parceria colaborativa na formaçáo de professores de Ciências: a Educação Inclusiva em questấo. In: GUIMARÃES, O. M. (Org.). Conhecimento Químico: desafios e possibilidades na ação docente: Encontro Nacional de Ensino de Química. Curitiba: Imprensa Universitária da UFPR, v. 1, p. 1-12, 2008.

BENITE, A. M. C.; et al. Formação de professores de Ciências em Rede Social: uma perspectiva dialógica na Educação Inclusiva. Revista Brasileira de Pesquisa em Educaçáa em Ciências. v. 9, n. 3, 2009.

BRASIL, Ministério da Educação. Parâmetros Curriculares Nacionais para o Ensino Médio. Brasília: MEC, 1998.

BRASIL. Constituiçáo da República Federativa do Brasil. Brasília: Senado, 1998.

Ministério da Educação. Conselho Nacional de Educação. Câmara da Educação Básica. Resoluçáo CNE/CEB 2/2001. Diário Oficial da União, Brasília, 14 de setembro de 2001, Seção 1E, p. 39-40, 2001. 23, 2002 .

Parecer CNE/CEB n. 4/2002. Diário Oficial da Uniâo, Brasília, 22 de fevereiro de 2002, Seção 1, p.

Ministério da Educação. Secretaria de Educação Especial. Programa Educação Inclusiva: direito à diversidade, 2003.

CAMPOS, R. C; SILVA, R. C. Funçốes da Química inorgânica funcionam? Química Nova na Escola, v. 9, 1999.

DRIVER, R.; NEWTON, P.; OSBORNE, J. Establishing the norms of scientific argumentation in classrooms. Science Education, v. 84, n. 3, p. 287-312, 2000.

HABERMAS, J. A inclusáo do outro: Estudos de Teoria Política. São Paulo: Loyola, 2007.

HADDAD, S. Educação e exclusão no Brasil. Em Questão, v. 3, 2007.

HODSON, D. Teaching and Learning about Science. Rotterdam: Sense Publishers, 2009.

HODSON, D. Teaching and Learning Chemistry in the Laboratory: A Critical Look at the Research. Educación Química, v. 16, n. 1, p. 60-68, 2005. 
LEMKE, J. L. Teaching all the languages of science: words symbols, images, and actions. Disponível em $<$ http://academic.brooklyn.cuny.edu/education/jlemke/papers/barcelon.htm>. Acesso em: 13, jun. 2014.

MANTOAN, M. T. E. Igualdade e diferença na escola: como andar no fio da navalha. In: AMORIM, V. (Org.). Inclusáo escolar: pontos e contrapontos. Sáo Paulo: Summus, 2006.

PEREIRA, L. L. S.; BENITE, C. R. M.; BENITE, A. M. C. Aula de química e surdez: sobre interaçóes pedagógicas mediadas pela visão. Química Nova na Escola, v. 33, n. 1, 2011.

PROCÓPIO, M. V. R.; et al. Formação de professores em ciências: um diálogo acerca das altas habilidades e superlotação em rede colaborativa. Revista Eletrônica Enzenanza de la Ciências, v. 9, p. 435-456, 2010.

PROCOPIO, M.V.R.; et al. Formaçáo de professores em ciências: um dialógo acerca das altas habilidades e superdotaçáo em rede colaborativa. Revista Eletrônica Enzenanza de La Ciencias, v. 9, n. 2, p. 1-22, 2010.

RODRIGUES, D. (Org.). Inclusão e educaçáo: doze olhares sobre a educaçăo inclusiva. São Paulo: Summus Editorial, 2006.

SOUSA, S. F.; SILVEIRA, H. E. Terminologias químicas em Libras: a utilização de sinais na aprendizagem de alunos surdos. Química Nova na Escola, v. 33, n. 1, 2011.

VITALIANO, C. R. Diagnóstico das necessidades de preparação dos professores de cursos de licenciatura para incluir estudantes com necessidades especiais e formar futuros professores aptos a promover a inclusão. In: ALMEIDA, M. A.; MENDES, E. G.; HAYASHI, M. C. P. I.(Orgs.). Temas em Educaçáo Especial: múltiplos olhares. São Paulo: Junqueira \& Marin, 2008.

\section{Correspondência}

Anna Maria Canavarro Benite - Universidade Federal de Goiás, Instituto de Química. Campus Samambaia IQ I - Itatiaia. CEP: 74001-970, Goiânia, Goiás - Brasil - Caixa-postal: 131.

E-mail: anna@quimica.ufg.br - crbenite@gmail.com - eveline_vilela@yahoo.com.br

Recebido em 20 de junho de 2014

Aprovado em 15 de outubro de 2014 
